\title{
ИСПОЛЬЗОВАНИЕ ПРОГРАММЫ ТRЕQ В ПОЛЬСКО-РУССКОМ ПЕРЕВОДЕ
}

\section{Using the Treq Program in Polish-Russian Translation}

Keywords: Treq, InterCorp, translation equivalence, Polish, Russian, Czech

Contact: Uniwersytet Ślaskiw Katowicach; aleksandrazieba33@gmail.com

Программа Treq, использованию которой будет посвящена настоящая статья, представляет собой электронный инструмент, обеспечивающий поиск переводных эквивалентов на базе корпуса InterCorp. Последний подразумевает под собой проект, целью которого является создание обширного параллельного синхронного корпуса текстов, охватывающего как можно больше языков. Это открытый корпус, т.е. он постоянно пополняется новыми текстами. Последняя тринадцатая версия 2020 года включает в себя публицистические тексты и новости с сайтов Project Syndicate и VoxEurop, юридические тексты корпуса Acquis Communautaire, отчеты с заведений Европейского парламента Europarl, субтитры к фильмам из платформы OpenSubtitles, переводы Библии и художественные тексты (так называемые ядро). Упомянутые источники не фиксируют текстов на всех языках, поэтому для каждой отдельной переводной лексикографии InterCorp создает лучшие или худшие условия для работы переводчика. Сама идея зародилась в Праге в Карловом университете в 1994 году. Инструмент Treq относительно молодой, а его исходная версия (альфа 0.1) датируется сентябрем 2014 года и быстро набирает популярность среди пользователей, особенно благодаря своей простоте (Škrabal, Vavřín 2017: 246). Авторы предположили, что программа адресована не только специалистам (переводчикам, лексикографам), а также для всех тех, кто в средней степени владеет конкретным языком или его изучает (ученики, студенты и т.п.). Несложность и доступность приложения обладает также существенным недостатком - нет возможности провести расширенный многофакторный анализ. До недавнего времени языками интерфейса программы Treq выступали исключительно либо чешский, либо английский, которые считались обязательными из сопоставляемых друг с другом языков. Однако настоящая 
версия базы переводных эквивалентов 2.1, созданная в июле 2020 года, позволяет дополнительно искать доступные переводы и синонимы для испанского языка, что делает Treq надежным инструментом не только для богемистов и англистов, а также тех, кто связан с широко понимаемой испанистикой. Необходимо добавить, что в настоящее время указанное приложение пользуется уже двенадцатой версией корпуса InterCorp, что значительно увеличивает количество доступных текстов и тем самым возможности получения правильного перевода. Для использования данного набора двуязычных словарей, нужен только веббраузер (http://treq.korpus.cz), а поиск эквивалентов возможен без предварительной регистрации для всех пользователей. В первую очередь надо указать желаемую языковую пару, выбрав исходный язык (язык запроса) и целевой язык (язык потенциальных эквивалентов). Потом необходимо ввести в соответствующую колонку языковую единицу, переводной эквивалент которой нам нужен. Затем пользователь может ввести свой запрос (Query) и нажать кнопку Search.

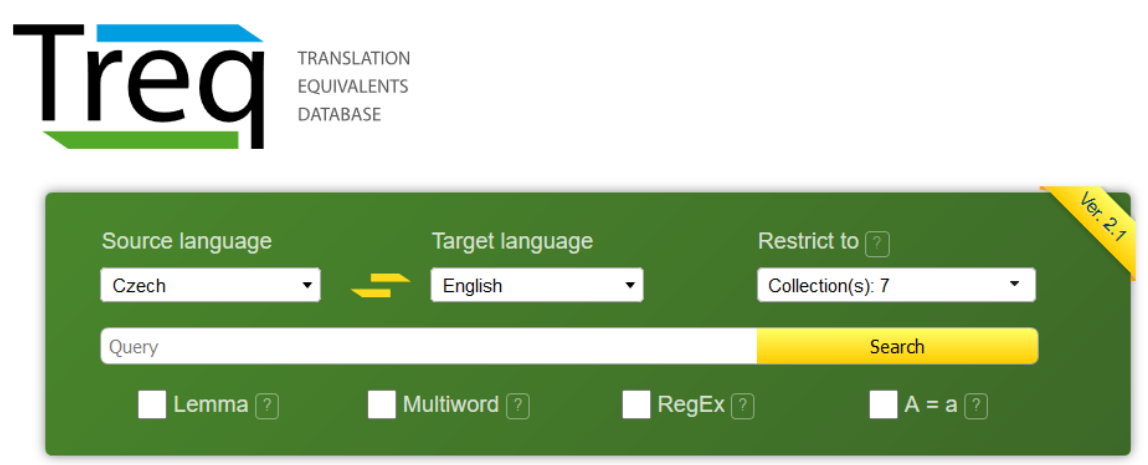

Результатом поиска будут всевозможные эквиваленты перевода данного слова на целевой язык, причем автоматически отсортированные по убыванию частоты и с учетом процентных долей в общем объеме. Кроме вышеуказанных функций, программа Treq предоставляет возможность проверить контексты перевода выбранного нами слова, а также посмотреть его вхождения в InterCorp. Приложение содержит также дополнительные инструменты (функции), облегчающие поиск нужного нам транслята. Функция Lemma обнаружит все словоформы одной и той же лексемы, благодаря чему пользователь получит значительно больше число вхождений. К примеру, приведем вхождения русской лексемы хлеб в следующем порядке: число вхождений, процентная доля, русский транслянд, чешский транслят: 


\section{без функции Lemma}

\begin{tabular}{|c|c|c|c|}
\hline$\Delta$ Frequency $\nabla$ & $\Delta$ Proportion $\boldsymbol{\nabla}$ & $\Delta$ Russian $\boldsymbol{\nabla}$ & $\Delta$ Czech $\nabla$ \\
\hline 166 & 48.7 & хлеб & chléb \\
\hline 159 & 46.6 & хлеб & chleba \\
\hline 6 & 1.8 & хлеб & $\underline{\text { obili }}$ \\
\hline 3 & 0.9 & хлеб & Chleba \\
\hline 1 & 0.3 & хлеб & $\underline{\text { chlebu }}$ \\
\hline 1 & 0.3 & хлеб & zájmem \\
\hline 1 & 0.3 & хлеб & chlebem \\
\hline 1 & 0.3 & хлеб & rušených \\
\hline 1 & 0.3 & хлеб & $\underline{\text { Obili }}$ \\
\hline 1 & 0.3 & хлеб & pečivo \\
\hline 1 & 0.3 & хлеб & houska \\
\hline 341 & & & \\
\hline
\end{tabular}

\section{c функцией Lemma}

\begin{tabular}{|c|c|c|c|}
\hline$\Delta$ Frequency $\boldsymbol{\nabla}$ & $\Delta$ Proportion $\boldsymbol{\nabla}$ & $\Delta$ Russian $\boldsymbol{\nabla}$ & $\Delta$ Czech $\nabla$ \\
\hline 905 & 89.2 & хлеб & chléb \\
\hline 66 & 6.5 & хлеб & obili \\
\hline 11 & 1.1 & хлеб & jídlo \\
\hline 6 & 0.6 & хлеб & Chlebo \\
\hline 3 & 0.3 & хлеб & jist \\
\hline 2 & 0.2 & хлеб & nádraži \\
\hline 1 & 0.1 & хлеб & sedmý. \\
\hline 1 & 0.1 & хлеб & žemle \\
\hline 1 & 0.1 & хлеб & obživa \\
\hline 1 & 0.1 & хлеб & louka \\
\hline 1 & 0.1 & хлеб & jeden \\
\hline 1 & 0.1 & хлеб & dostávat \\
\hline 1 & 0.1 & хлеб & $\underline{\text { věc }}$ \\
\hline 1 & 0.1 & хлеб & nějaký. \\
\hline 1 & 0.1 & хлеб & drobek \\
\hline 1 & 0.1 & хлеб & Bubbie \\
\hline 1 & 0.1 & хлеб & předpisovat \\
\hline 1 & 0.1 & хлеб & $\underline{\text { żvanec }}$ \\
\hline 1 & 0.1 & хлеб & pečivo \\
\hline 1 & 0.1 & хлеб & $\underline{\text { nasytit }}$ \\
\hline 1 & 0.1 & хлеб & koláček \\
\hline 1 & 0.1 & хлеб & $\underline{\text { huba }}$ \\
\hline 1 & 0.1 & хлеб & bochnik \\
\hline 1 & 0.1 & хлеб & $\underline{\text { živobytí }}$ \\
\hline 1 & 0.1 & хлеб & õeá \\
\hline 1 & 0.1 & хлеб & $\underline{\text { kaše }}$ \\
\hline 1 & 0.1 & хлеб & cože \\
\hline 1 & 0.1 & хлеб & rušený. \\
\hline 1015 & & & \\
\hline
\end{tabular}


Не будет особым преувеличением сказать, что существенные различия в количестве чисел очевидны - введение единицы с функцией Lemma обнаруживает почти в 3 раза больше ответов, чем без использования данного инструмента. Помимо этого, запрос может быть введен также как многословная единица (Multiword), либо с использованием регулярных выражений (RegEx). Пользователям также предоставляется возможность введения запроса без различения программой прописных и строчных букв $(\mathrm{A}=\mathrm{a})$. Последним является параметр Restrict to, с помощью которого извлечение результатов может быть нацелено на разные типы текста: основные тексты, ориентированные на художественную литературу, определенные коллекции или весь корпус. Однако, следует учитывать тот факт, что ограничение выбора корпусных ресурсов приведет не только к снижению числа вхождений, а также к меньшей достоверности полученных данных. Все эти факторы несомненно осложняют проведение правильного анализа или делают его невозможным.

Нельзя и не заметить того факта, что в программе осуществляется выравнивание текстов по словам, происходящее автоматически и практически не пересматриваемое. Указанную особенность создатели Treq описывают следующим образом:

Originální a překladové texty jsou nejprve na základě statistických výpočtu zarovnány po slovech pomocí programu GIZA++ (Och-Ney 2003). Zarovnané dvojice slov jsou pak setřídèny a sumarizovány. Výsledek automatické excerpce neni nijak revidován, jako ukazatel relevance překladového ekvivalentu však může posloužit relativní frekvence př́slušné dvojice slov. Čím častěji se ekvivalent zadaného slova vyskytl ve srovnání s ostatními ekvivalenty, tím větši je pravděpodobnost, že je funkční (Treq, Nápověda, электронный ресурс).

При подготовке данных для Treq из всего корпуса выбираются только предложения, выровненные методом 1:1, что позволяет в большей степени предотвращать потенциальные ошибки. В более старых версиях программы использовался метод пересечения, который создавал только такие выравнивания, при которых одно слово на исходном языке соответствует одному эквиваленту на целевом языке. Как уже было написано, инструмент Treq предоставляет пользователю дифференцированные условия для поиска эквивалентов, что обусловлено выбором исходного и целевого языков. На это влияют модули конкретных языков, содержащие в параллельном корпусе и отличающиеся друг от друга количеством текстов и определенных жанров. К примеру, двенадцатая версия польского корпуса насчитывает свыше 87 млн. слов, а русского - примерно 19 млн. лексических единиц и выражений. В дополнение к этому польские 
и русские коллекции, содержащиеся в InterCorp v12 полностью не совпадают. Польский InterCorp содержит все коллекции InterCorp за исключением публицистических текстов на сайте Project Syndicate. C другой стороны, имеется русский InterCorp, включающий в себя художественные тексты, публицистические тексты и субтитры на сайте OpenSubtitles.

Совершенно разные условия для перевода и наличие исключительно трех языков запроса могут привести к ощущению, что данная программа не представляет собой пригодного переводческого инструмента для польского русиста или русского полониста. Однако для пользователей, которые знакомы с основами чешского, английского либо испанского языков, Treq может служить вспомогательным инструментом в процессе перевода (напр., польско-чешского, русско-чешского и т.д.). Чтобы доказать полезность программы в процессе польско-русского перевода и описать возможность выступления потенциальных ошибок, выберем конкретные лексические единицы и попробуем получить правильный эквивалент путем сопоставления польско-чешских и чешско-русских результатов перевода. Для иллюстрации будем использовать многозначную польскую лексему paczek, для которой попытаемся найти верный русский транслят посредством чешского перевода. Обращение к печатным или электронным одноязычным и переводным словарям, т.е. к основным источникам материала, приносит следующие ответы.

Объяснение значений лексемы paczek представляет электронный «Wielki słownik języka polskiego», основной материальной базой которого является Национальный корпус польского языка (NKJP). Первое значение подразумевает под собой часть растения, состоящую из зачатков стеблей, листьев и побегов, второе - круглое дрожжевое печенье с начинкой из розового джема, фруктов, ликера, пудинга и т.д., жаренное во фритюре. Более точное толкование данного слова приводит «Słownik języka polskiego PWN», в котором дополнительно узнаем, что paczek - это отдельная часть стволового организма в виде клетки, комплекса клеток или тканей, которая превращается в организм-потомок (выступает у растений и низших животных). В свою очередь, только «Wolny, wielojęzyczny Wikisłownik» (pl.wiktionary.org) отмечает лексему pączek как диминитивную форму слова $p q \varepsilon$. Нельзя не заметить того факта, что никакой из перечисленных источников не фиксирует очень распространенного и разговорного значения этой лексической единицы, т.е. paczek 'толстый мальчик'. Как легко можно догадаться, с точки зрения перевода в центре нашего интереса будет значение данной лексемы как разновидности пищи, которое характеризируется наибольшей употребительностью. 
Обратимся сейчас к переводным словарям, чтобы установить потенциальные трансляты: «Polsko-czeski słownik LINGEA 5» (https://dict.com/czesko-polski/paczek) приводит следующие переводные эквиваленты для лексемы paczek: 1. (на дереве) pupen, (розы и т.п.) роире̌; 2. (печенье) koblih. Проверка семантики данных слов на сайте ssjc.ujc.cas.cz (Slovník spisovného jazyka českého) позволяет частично подтвердить соответствие смыслового значения польских и чешских лексических единиц.

В свою очередь, бумажный «Wielki słownik polsko-rosyjski PWN» рекомендует использование следующих возможных транслятов для слова pqczek: 1. почка (в растении); 2. бутон (цветочный на ветке, стебле); 3. пышка (хлебобулочное изделие кольцеобразной формы); 4. пончик (жареная булочка).

С другой стороны, «Польско-русский и русско-польский словарь» Г.В Ковалевой не отмечает лексемы пышка в качестве надежного переводного эквивалента. Необходимо еще подчеркнуть, что слово пончик - польского происхождения, а помимо этого, указанную лексему в русском языке употребляется преимущественно для обозначения печенья с дыркой, которая никак не напоминает польской сладкой булочки. В таком случае, многократно к слову пончик добавляется прилагательное польский или словосочетание с начинкой, чтобы адресат точно сообразил себе печенье, которое автор имеет ввиду. В ходе исследования семантического значения приведенных эквивалентов себя обнаружила несколько неожиданная особенность, состоящая в том, что русские одноязычные словари фиксируют значение слова пончик как пренебрежительное название ребенка с лишним весом. Как уже было отмечено, польские словарные ресурсы не замечают значения данной лексемы в контексте обозначения лица, несмотря на то что они зафиксированы в корпусе. К примеру:

Mówia na niego Psychol. Kiedyś nie wychodził z domu dla gier, ale od kiedy ma internet nic się nie liczy... Wygląda jak paczek. Przed kompem czas szybko leci.

После разъяснения возможных дефиниции слова paczek и определения потенциальных русских и чешских эквивалентов, попытаемся сейчас при помощи программы Treq найти подходящий перевод для обозначения круглого шарика с вареньем внутри. Сначала назначим, что исходным языком будет польский, а целевым чешский с использованием функции Lemma для получения более достоверных ответов. Результаты поиска представляются следующим образом (из-за ограничений в объеме статьи не приводим все вхождения). 
Таблица 1. Treq для запроса paczek.

\begin{tabular}{|c|c|c|c|}
\hline $\begin{array}{c}\text { Число вхождений } \\
\text { (Frequency) }\end{array}$ & $\begin{array}{c}\text { Процентная доля } \\
\text { (Proportion) }\end{array}$ & $\begin{array}{c}\text { Польский } \\
\text { транслянд } \\
\text { (Polish) }\end{array}$ & $\begin{array}{c}\text { Чешский } \\
\text { эквивалент } \\
\text { (Czech) }\end{array}$ \\
\hline 201 & 60,2 & pączek & kobliha \\
\hline 17 & 5,1 & pączek & poupě \\
\hline 10 & 3,0 & pączek & pupen \\
\hline 8 & 2,4 & pączek & koblížek \\
\hline 7 & 2,1 & pączek & kompot \\
\hline
\end{tabular}

Полученные данные являются результатом автоматического корпусного анализа, который безусловно может включать в себя многочисленные ошибки. Они могут вытекать как из неправильной аннотации, так из омонимии. Имея дело с программой Treq, которая не различает значения многозначных единиц, мы должны осознавать, что предложенные эквиваленты на самом деле могут не являться теми, которых мы ищем. В данном случае потенциальные чешские переводы слова pqczek следует считать достоверными согласно с ранее приведенной словарной информацией. Ручной анализ контекстов подтверждает верность перевода, однако число вхождений (201) не совпадает с числом доступных контекстов (280). Внимание еще привлекает различие в грамматической категории рода существительного - словарь «LINGEA» предлагал употребление мужской формы koblih, в то время как Treq фиксирует преимущественное использование слова kobliha (женский род). Как оказывается, первый вариант является диалектизмом, сильно нераспространенным в повседневной речи, в силу чего нельзя считать его правильным эквивалентом (https://czechtongue.cz/kobliha-x-koblih/). Замеченное несоответствие позволило доказать, что программа Treq лучше работает с поиском надежного транслята. Переведем сейчас чешское слово kobliha как эквивалент лексемы paczek на русский язык.

Таблица 2. Treq для запроса kobliha.

\begin{tabular}{|c|c|c|c|}
\hline $\begin{array}{c}\text { Число вхождений } \\
\text { (Frequency) }\end{array}$ & $\begin{array}{c}\text { Процентная доля } \\
\text { (Proportion) }\end{array}$ & $\begin{array}{c}\text { Чешский } \\
\text { транслянд } \\
\text { (Сzech) }\end{array}$ & $\begin{array}{c}\text { Русский } \\
\text { эквивалент } \\
\text { (Russian) }\end{array}$ \\
\hline 14 & 21,5 & kobliha & пончик \\
\hline 8 & 12,3 & kobliha & пончики \\
\hline 6 & 9,2 & kobliha & пирог \\
\hline 6 & 9,2 & kobliha & пончиками \\
\hline 5 & 7,7 & kobliha & пирожок \\
\hline
\end{tabular}


В данном случае предложенный нами способ перевода польской лексемы paczek на русский язык при помощи программы Treq можно считать успешным. Небольшое число вхождений и некоторые замеченные контекстные ошибки не могут полностью отрицать верность полученного эквивалента. Хотя результаты поиска не фиксируют наиболее адекватного перевода, т.е. пончик с начинкой, то нельзя их считать недостоверными. Польско-русские словари рекомендуют тот же эквивалент, что обусловлено высокой степенью применения лексемы пончик на фоне доступных переводов. Чтобы пользователь мог абсолютно убедиться в правильности перевода, лучше верифицировать отдельные вхождения во избежание многочисленных ошибок.

Процесс перевода при помощи программы Treq сильно осложняется в случае поиска многолексемных единиц (Multiword). В данном случае лучше дополнительно использовать функцию регулярные $(\mathrm{RegEx})$, благодаря которой можем формировать более сложные запросы. Регулярные слова включают в себя специальные символа, что позволяет выявить конкретный набор слов. Регулярные слова состоят: 1. из специальных символов; 2 . из специальных и альфанумерических символов; 3. из альфанумерических символов (Charciarek 2020: 126).

Указанная функция дает возможность выявить возможные варианты как трансляндов, так и транслятов. В данном месте попробуем перевести польское наименование очередного сладкого пищевого продукта, т.е. bita śmietana на русский язык посредством чешского перевода. На этот раз проверку доступных эквивалентов, содержащихся в переводных польско-чешских и польско-русских словарях, сделаем после анализа программы Treq.

Таблица 3. Treq для запроса bita śmietana.

\begin{tabular}{|c|c|c|c|}
\hline $\begin{array}{c}\text { Число вхождений } \\
\text { (Frequency) }\end{array}$ & $\begin{array}{c}\text { Процентная доля } \\
\text { (Proportion) }\end{array}$ & $\begin{array}{c}\text { Польский } \\
\text { транслянд } \\
\text { (Polish) }\end{array}$ & $\begin{array}{c}\text { Чешский } \\
\text { эквивалент } \\
\text { (Czech) }\end{array}$ \\
\hline 2 & 50,0 & bita śmietana & šlehačku \\
\hline 1 & 25,0 & Bita śmietana & Šlehačka \\
\hline 1 & 25,0 & bita śmietana & šlehačka \\
\hline
\end{tabular}

Как видно из приведенной таблицы, процентная доля предлагаемых эквивалентов распределяется равномерно. В то время как филолог сразу будет догадываться, что первой транслят представляет собой винительный падеж слова šlehačka, то для тех, кому не вполне знакомы грамматические правила склонений слов, нужно будет дополнительно проверить ту информацию, чтобы выбрать правильный эквивалент. Помимо этого, у некоторых еще может вызвать сомнения 
тот факт, что многолексемная польская единица имеет однословный эквивалент в чешском языке. Не проверяя в словарях адекватности предлагаемого программой перевода, попытаемся найти русский эквивалент при использовании лексемы šlehačka.

Таблица 4. Treq для запроса šlehačka.

\begin{tabular}{|c|c|c|c|}
\hline $\begin{array}{c}\text { Число вхождений } \\
\text { (Frequency) }\end{array}$ & $\begin{array}{c}\text { Процентная доля } \\
\text { (Proportion) }\end{array}$ & $\begin{array}{c}\text { Чешский } \\
\text { транслянд } \\
\text { (Czech) }\end{array}$ & $\begin{array}{c}\text { Русский } \\
\text { эквивалент } \\
\text { (Russian) }\end{array}$ \\
\hline 1 & 33,3 & Šlehačka & Сливки \\
\hline 1 & 33,3 & Šlehačka & Взбитые сливки \\
\hline 1 & 33,3 & šlehačka & $\begin{array}{c}\text { Клочья сливок } \\
\text { заляпали }\end{array}$ \\
\hline
\end{tabular}

Такие результаты запроса заставляют пользователя проверить возможные эквиваленты в достоверных словарных источниках, потому что обнаруженные программой переводы обладают той же частотностью выступления в корпусных текстах. Такая ситуация нередко делает невозможным сразу выбрать адекватный перевод. В упомянутом уже словаре Г.В. Ковалевой имеется информация, что в качестве эквивалента для многолексемной единицы bita śmietana применяется русский перевод взбитые сливки. Данный пример доказал, что программе в конечном итоге удалось найти подходящий эквивалент, однако необходима предварительная проверка возможных транслятов в бумажных и электронных словарях. Чтобы полезность программы не подвергалась дальнейшим сомнениям, необходимо еще проверить, как Treq устанавливает эквиваленты для определенных фразеологизмов, часто употребляемых в повседневной речи. Наша цель - установить русский эквивалент распространенного польского фразеологизма butka z mastem 'разг. что-то очень простое для исполнения'. Электронный словарь «GLOSBE», в котором есть возможность ввести многолексемный запрос, в качестве чешского эквивалента рекомендует употребление слова hračka вместе со вспомогательным глаголом быть (напр. Byla to hračka) или без него (напр. úplná hračka). В свою очередь, для русского языка предлагаются три эквивалента: 1. проще пареной репь; 2. раз плюнуть; 3. как два пальца обоссать, которые несомненно сильно отличаются друг от друга разными стилистическими оттенками: проще пареной репь принадлежит к разговорной речи, раз плюнуть к просторечию, а фразеологизм как два пальца обоссать считается вульгаризмом. После проверки возможных переводов обратимся к программе с целью установления верного русского транслята посредством чешского перевода: 
Таблица 5. Treq для запроса butka z mastem.

\begin{tabular}{|c|c|c|c|}
\hline $\begin{array}{c}\text { Число вхождений } \\
\text { (Frequency) }\end{array}$ & $\begin{array}{c}\text { Процентная доля } \\
\text { (Proportion) }\end{array}$ & $\begin{array}{c}\text { Польский } \\
\text { транслянд } \\
\text { (Polish) }\end{array}$ & $\begin{array}{c}\text { Чешский } \\
\text { эквивалент } \\
\text { (Сzech) }\end{array}$ \\
\hline 13 & 15,7 & Bułka z masłem & hračka \\
\hline 5 & 6,0 & Bułka z masłem & Je to hračka \\
\hline 5 & 6,0 & Bułka z masłem & Hračka \\
\hline 4 & 4,8 & Bułka z masłem & Byla to hračka \\
\hline 4 & 4,8 & bułka z masłem & hračka \\
\hline
\end{tabular}

Дополнительная проверка отдельных вхождений позволяет доказать, что эквивалентом польского фразеологизма является употребление слова hračka с разными формами вспомогательного глагола, к примеру: A jak u Ciebie? - Butka z mastem. I A co ty? - Opravdu to byla hračka. Сравнивая указанные результаты поиска и найденный в электронном словаре чешский эквивалент, можно прийти к выводу, что Treq безусловно предлагает пользователю правильный транслят. Последним этапом нашей работы будет установление подходящего русского перевода при использовании чешского выражения Je to hračka.

Таблица 6. Treq для запроса Je to hračka.

\begin{tabular}{|c|c|c|c|}
\hline $\begin{array}{c}\text { Число вхождений } \\
\text { (Frequency) }\end{array}$ & $\begin{array}{c}\text { Процентная доля } \\
\text { (Proportion) }\end{array}$ & $\begin{array}{c}\text { Чешский } \\
\text { транслянд } \\
\text { (Сzech) }\end{array}$ & $\begin{array}{c}\text { Русский } \\
\text { эквивалент } \\
\text { (Russian) }\end{array}$ \\
\hline 1 & 16,7 & Je to hračka & Проще простого \\
\hline 1 & 16,7 & Je to hračka & пофиг \\
\hline 1 & 16,7 & Je to hračka & Кусок торта \\
\hline 1 & 16,7 & Je to hračka & Проще \\
\hline 1 & 16,7 & Je to hračka & Легко \\
\hline
\end{tabular}

В данном случае уже на первый план выдвигаются проблемы, связанные не только с небольшим числом выступлений указанных единиц в корпусе, а также с тем, что они никаким образом не совпадают с ранее отмеченными возможными переводами. С целью решения данного вопроса мы прибегли к НКРЯ, чтобы проверить частотность употребления каждого предлагаемого программой и словарем транслята. К нашему удивлению оказалось, что самым распространенным русским выражением для определения чего-то очень простого является первый эквивалент из программы Treq, т.е. Проще простого (246 вхождений). Интересно получилось, что одинаковое число вхождений всех транслятов и их малое количество не показались препятствием для инструмента, который все-таки зафиксировал наиболее подходящий перевод. Однако 
недостатком в этом случае может быть тот факт, что программа не предложила перевода выражения butka z mastem в его буквальном значении (вид пищи).

На фоне проведенного анализа выбранных нами слов можно подытожить, что приложение Treq лучше применяется при поиске перевода однолексемных единиц исходного языка. Весь процесс осуществляется достаточно быстро и эффективно, а пользователь не должен обязательно обладать одним из трех языков интерфейса программы, чтобы найти нужный ему эквивалент. В подавляющем большинстве случаев инструмент предлагает достоверный перевод, но исследование контекстов их употребления только поможет убедиться в правильности эквивалента. Полезность программы Treq для польско-русского перевода - несомненна, о чем свидетельствуют указанные в статье примеры найденных транслатов и способы их поиска. Несложно решить разные переводческие задачи, благодаря обширному списку текстовых эквивалентов, которые делают Treq одним из самых достоверных электронных словарей.

Однако не следует забывать о том, что представленный корпусной материал содержит большое количество существенных ошибок, которые в первую очередь относятся к эквивалентам многолексемных единиц. В этом случае начинающий переводчик может извлечь из списка несоответствующий перевод, поэтому необходима высокая степень опытности пользователя, чтобы решить неоднозначные вопросы. Большие сомнения может вызывать и малое число вхождений, которое заставляет сделать детальное исследование предлагаемых транслятов, как получилось в случае проанализированного нами фразеологизма butka z mastem. Необходимо еще напомнить, что большая разница в числе доступных польских и русских коллекций значительно влияет на репрезентативность и достоверность полученных корпусных данных. Увеличение ресурсов InterCorp несомненно повысило бы вероятность выступления искомого эквивалента. Надеемся, что большой объем польского корпуса позволит в будущем включить тот язык в ряд доступных языков интерфейса программы Treq, благодаря чему процесс польско-русского перевода безусловно облегчится.

\section{Summary}

The purpose of this article is to present the Treq program and to describe how to use this electronic tool in the Polish-Russian translation process. The author shows the available functions of the program that make it easier to find the needed equivalent. The author provides information on the number of the collections included in the InterCorp corpus. In addition, the article contains specific examples illustrating the usage of the Treq 
application in the lexicography of the Polish-Czech and the Czech-Russian translations. The analysis of one-word and multi-word lexemes, as well as translation of phraseological expressions allowed us to draw concrete conclusions referring to the advantages and disadvantages of the application. The usefulness of the program in the process of the Polish-Russian translation is emphasized. At the same time the article shows the ways of avoiding the potential mistakes.

\section{Literatura}

Škrabal, M., Vavř́n, M. Databáze překladových ekvivalentů Treq. Časopis pro moderni filologii. 2017 (99), s. 245-260.

Charciarek, А. Программа для установления переводных эквивалентов Treq: преимущества и недостатки. Studia Rossica Posnaniensia. 2020 (45/1), с. 121132.

Vavř́n, M., Rosen, A. Treq. FF UK. Praha, 2015. Режим доступа: http://treq.korpus.cz. 